\title{
Methylmalonic Aciduria and Homocystinuria, cblC Type
}

National Cancer Institute

\section{Source}

National Cancer Institute. Methylmalonic Aciduria and Homocystinuria, cblC Type. NCI

Thesaurus. Code C142174.

An autosomal recessive form of combined methylmalonic aciduria and homocystinuria, caused by mutation(s) in the MMACHC gene, encoding methylmalonic aciduria and homocystinuria type $\mathrm{C}$ protein. 